\title{
Evolution Mechanism on the Unsafe Behavioural Risks of General Aviation Pilots
}

\author{
Xinyao Guo ${ }^{*}$, Yue Chen², Qingmin $\mathrm{Si}^{1}$, Yuansheng Wang ${ }^{3}$ \\ ${ }^{1}$ School of Civil Aviation, Zhengzhou University of Aeronautics \\ No. 15 Wenyuan West Road, Zhengdong New District, Zhengzhou, Henan, China \\ E-mail.*xyguo@zua.edu.cn; siqingmin@163.com \\ *Corresponding author \\ ${ }^{2}$ Draexlmaier (Benxi) Automotive Electrics Co., Ltd. \\ No.1 Draexlmaier Road, Benxi Manchu Autonomous County, Benxi, Liaoning, China \\ E-mail.Clare.Chen@draexlmaier.com \\ ${ }^{3}$ School of Aviation, Anyang Institute of Technology \\ West of Huanghe Road, High-tech District, Anyang, Henan, China \\ E-mail.mingbeire@163.com \\ cross $^{\text {ref }}$ http://dx.doi.org/10.5755/j01.ee.32.2.28162
}

The unsafe behaviour prevention and control of general aviation pilots has become an emphasis in the general aviation safety management with the increasing number of general aviation enterprises, lengthening of flight time and frequent occurrence of public safety events caused by general aviation accidents. How to identify the factors influencing the unsafe behaviours of general aviation pilots and clarify the inter factor evolution mechanism is hot issue in the general aviation. To accurately identify the key factors influencing the unsafe behaviours of general aviation pilots and define the interaction mechanism between factors, using the unsafe behaviours of pilots in 200 global general aviation accidents during 2015-2019 and the association rule method, the bottom-layer factors of the Human Factors Analysis and Classification System (HFACS) model were analysed. Furthermore, the influence degree, influenced degree, centrality and causality of the influencing factors in the HFACS model were calculated, and the risk transfer path at different layers was determined on the basis of the integrated decision-making trial and evaluation laboratory (DEMATEL) and fuzzy theory. Results show that the poor individual ready state is strongly associated with skill error, decision-making error and habitual violation. Moreover, 11 factors, such as poor physical environment, physical/intelligence limitation and poor technical environment, constitute the factors in the cause group for pilot unsafe behaviours. 7 factors, such as insufficient supervision, improper operation plan and failure to discover and correct problems, are the factors in the result group. Illegal behaviour, failure to discover and correct problems and decision-making error of pilots, which are of high centrality, are key factors influencing the unsafe behaviours of general aviation pilots. The conclusions obtained from this study compensate the deficiencies for the linear statistical model of risk factors and provide a novel method for regulating and controlling the unsafe behaviours of general aviation pilots.

Keywords: General Aviation Pilot; Unsafe Behaviours; DEMATEL Method; Fuzzy Theory; Flight Safety; Risk Management and Control.

\section{Introduction}

The development of general aviation is supported by various countries across the globe, and the general aviation enterprises are enjoying the high-speed development in recent years. Accordingly, the number of aircrafts and the base number of flight hours are rapidly increased, and the general aviation accidents are continuously springing up. According to statistics, 107 general aviation accidents took place in China in the first half years of 2010-2020, which led to a death toll of 83 . The number of accidents caused by pilot unsafe behaviours and potential accidents remains at a high level. According to the survey of Accident Investigation Centre of Civil Aviation Administration of China on security incidents and accidents, the accidents arising out of pilot unsafe behaviours accounted for $58 \%$ in the total number of accidents. Therefore, human unsafe behaviours are the root cause for the accidents (Erjavac et al., 2019; Wurthmann, 2020). The human unsafe behaviours and the execution of standard operating procedure are not only influenced by congenital individual factors, such as physiological features, psychological features, knowledge level, pressure and fatigue. Figure 1 shows the incomplete statistics of reasons for general aviation pilots' unsafe behaviours from 2010 to 2019 of the world (Kyriakopoulos et al., 2020), but also closely related to the acquired individual factors of the pilots, such as cabin environment, organizational management conditions and man-machine system environment where the pilots are located; the relationships between the factors are also intricate (Piotr et al., 2020; Benlemlih, \& Cai, 2020). The basis for an effective regulation and prevention of security incidents lies in identifying and judging the factors influencing the unsafe behaviours of general aviation pilots, analysing the interaction between factors, exploring the risk transfer path and clarifying evolution mechanism. 
Statistics of reasons for pilot unsafe behavior
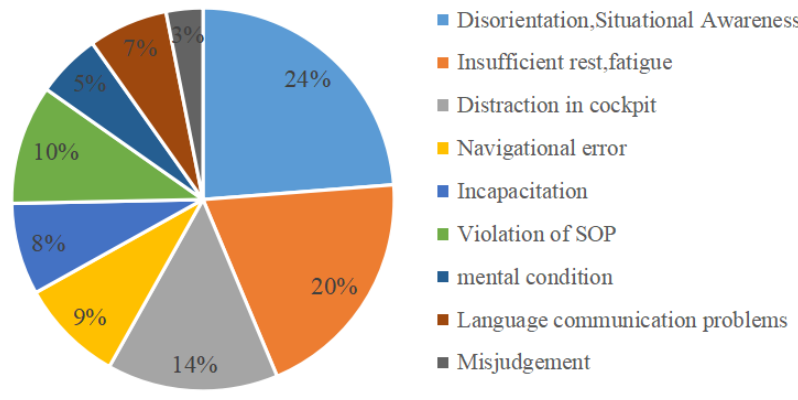

Figure 1. Statistics on the Reasons of Unsafe behaviours of General Aviation Pilots from 2010 to 2019

However, the existing studies regarding the regulation and control of unsafe behaviours of general aviation pilots mainly focus on the statistical analysis of their subjective behavioural mistakes or improvement of aircraft airworthiness technology or reliability; meanwhile, few studies have involved individual levels, such as the safety capability, safety awareness and psychological stress of behavioural mistakes causing the accidents, and the factors leading to individual mistakes, such as safety atmosphere, man-machine matching and equipment reliability (Ryffel et al., 2019; Mallika, 2019; Schultz, \& Seele 2019; Uribetxebarria et al., 2020; Usatorre et al., 2020). In studies on the generation mechanism of human factorinduced flight safety accidents in general aviation, the personal physiological indexes of pilots are collected and analysed with the eye tracker, fatigue monitor and blood pressure monitor (Catherwood, 2014). The decisionmaking mistakes in the flight process are judged through physiological parameters, or the modelling and simulation analytical methods are used to introduce the temporal and logical ideas into the accident analysis (Whinnery et al., 2005). The influences of human errors on the flight accident risk evolution are discussed from microlevels (Chaturvedi et al., 2016; Suhir, \& Mogford, 2015). In addition, the human factors influencing the flight safety accidents in general aviation are analysed in the current phase mainly based on the investigation reports. Nevertheless, the accident investigation reports mainly centre on the confirmation of responsibility and lack the corresponding description of deep causes for the accidents (e.g., operator's mental state, physical state, intelligence, the safety and skill training the operator accepts and the safety management system); hence, they fail to comprehensively reflect the factors influencing unsafe behaviours in the flight process (Casner, \& Geven, 2013; Xue et al., 2013; Huo, 2013). The exploration into the causes for pilot unsafe behaviours mainly aims to the behavioural mistake analysis of the risk accident subjects, while the management factors at the organizational level and the factors at employees' psychological level are scarcely discussed. Meanwhile, little attention is paid to the interaction between risk factors. In particular, the causal relationship and interaction mechanism between risk factors are not deeply investigated. Accordingly, the set of factors influencing unsafe behaviours was determined from multiple dimensions, the interactive relationships between the influencing factors and their relationship strengths were analysed, and the risk transfer path between the factors in the system was figured out. On this basis, the action mechanism of pilot unsafe behaviours in general aviation and the key indexes were proposed, thus providing related support for the general aviation enterprises to formulate pilot behavioural risk prevention and control measures.

\section{Literature Review}

The existing studies on pilot unsafe behaviours are mainly based on two ideas: accident-based statistical analysis and occurrence mechanism research of pilot unsafe behaviours. The studies based on statistical analysis of accidents mainly include: Scott et al. (2007) analysed the influences of organizational factors and security control on the generation of unsafe behaviours via the HFACS model; $\mathrm{Li}$ et al. (2008) analysed and investigated the 41 civil aviation accidents in China from 1999 to 2006 and pointed out that the factors correlated with the prerequisite for unsafe behaviours included unsafe supervision and organizational influence; the fallible decisions made by managers had a direct baring on the supervision practice, created psychological conditions for unsafe behaviours and indirectly damaged the performance of pilots, thus causing accidents; in the research on commercial aviation pilots in Australia, Dana et al. (2014) found out that the factors influencing pilot decision making could be classified into three types: organization, society and personal factors; the organizational factors included organizational culture and time-related pressure and fatigue; the social factors consisted of social culture and client pressure. During the research on pilot unsafe behaviours, scholars have obtained the factors influencing pilot unsafe behaviours through the statistical analysis of accidents at the beginning. Based on the statistical analysis of accidents, English et al. (2015) found that laziness, hedonism (pursuit of excitement and deliberate violation of regulations), viciousness and improvement of behaviours violating related procedures directly influenced pilot unsafe behaviours; Gan et al. (2015) used the HFACS model to analyse the collision accidents in the air and found that pilot unsafe behaviours were mainly caused by insufficient pilot training, inadequate initial matching and communication of crew members and ineffective supervision and management of training process. Liu (2019) conducted literature analysis, expert interview and questionnaire survey and included pilot unsafe behaviours into internal component factors (including risk perception, forward-looking memory, decision-making, attention, risk attitude, flight technology and fatigue) and external influencing factors (including severe environment, cockpit layout, automation system, working procedure, training and education, reward and punishment system, external communication and crew collaboration).

The existing studies on the occurrence mechanism of pilot unsafe behaviours, the influencing paths of various factors for pilot unsafe behaviours are mainly explored, and the models of pilot unsafe behaviours are established and verified. Accordingly, the influencing paths and degrees of the factors influencing pilot unsafe behaviours are obtained. You et al. (2009) screened out 27 key behavioural characteristics required by safe driving 
behaviours by analysing the operating characteristics of modern airline flight and combining the CRM and TEM models. They established an evaluation scale for safety behaviours in an airline flight under the Chinese cultural background through the literature analysis, expert interview and open-type questionnaire survey. This scale provided standard guidance and diagnostic basis for safety driving behaviours of pilots, including four dimensions, namely, automatic system cognition, interpersonal communication and cooperation, situational awareness and decision making and leadership and management. Ji et al. (2011) found that risk tolerance exerted an indirect influence on the safety operation behaviours by influencing the risk attitude through the structural equation modelling. Risk perception played a significant role in regulating the relationship between risk tolerance and safety operation behaviours. The negative influence of risk tolerance on the safety operation behaviours was gradually reduced with the increasing risk perception of pilots. Chen et al. (2014) explored the formation mechanism of pilot behaviours from the angles of organizational, group and individual factors and through an analysis by introducing a structural equation model. They found that the pilot's positive cognition of the company safety management system had significant positive influences on their safety motive, compliance and degree of participation. The safety motive would be high when the pilot's self-efficacy is high. These perceptions would directly contribute to the improvement of safety behaviours. In the research on the relationships of pilot attention, risk perception and flight experience with flight accident, Ming et al. (2018) found that pilot attention had a direct negative influence on their participation in the behaviour and indirectly influenced their participation by influencing the risk perception. Wang et al. (2013) analysed the formation mechanism of pilot behaviours in violation of regulations from the perspectives of procedure, equipment and pilot situational awareness and established the system dynamic model for the pilot behaviours in violation of regulations. The results showed that the intervention effect of the governing policy was gradually reduced compared with the initial intervention phase after the intervention policy was implemented for a certain period. The repressing effect on pilot behaviours in violation of regulations became evident with the continuous improvement of safety input and training effectiveness. The behaviours in violation of regulations could be controlled under an ideal state.

In summary, the research objects on pilot unsafe behaviours are mostly air transport pilots, and the main attention is paid to the errors and behaviours in violation of regulations at the operational level. Meanwhile, the errors and behaviours in violation of regulations at the management level and the factors at the level of employees' psychological cognition have been less concerned. The particular emphasis is laid on mathematical statistics and structural equation modelling. The correlations between the causes for unsafe behaviours have been scarcely analysed, not to mention to reveal the action mechanism of risk factors and the induction and evolution process of unsafe behaviours.

To cope with the deficiencies of the existing studies, the case statistics was firstly combined with the analytical method of association rules to discuss about the association relationships between the factors influencing human unsafe behaviours in the HFACS analytical model. Secondly, the interfactor influence matrix was established using the integrated decision laboratory analytical method. The centrality and causality of each factor were calculated, the threshold values were set, and the strong influencing relationships between factors were screened out. The causal relationships between the influencing factors were then comprehensively analysed to find the key factors influencing the unsafe behaviours of general aviation pilots, which were taken as the priorities of the risk management and control. The other factors were gradually improved. This research facilitates managers to clarify the emphases in the unsafe behaviour risk regulation and control.

The remainder of this paper is organised as follows: Section 3 expounds the analytical framework for the unsafe behaviours of general aviation pilots, model analytical method, fuzzification of original data, establishment of influence matrix and calculation of centrality and causality. Section 4 presents the result analysis. Section 5 draws the related conclusions obtained from this study.

\section{Methodology}

HFACS, a classical human factors analysis model for aviation safety accidents, can analyse all human factors causing the accidents in details from different levels (Salmon et al., 2012). This model was proposed on the basis of the reason accident causation model (Swiss Cheese Model) to comprehensively analyse human mistakes (Neuhaus et al., 2015). The model has well solved the longterm separation status of human error theory from its practical application, and it is also a commonly accepted human factor classification tool in the investigation on aviation flight accidents. The HFACS model defines the failures at four levels: unsafe behaviours, preconditions for unsafe behaviours, unsafety supervision and organizational management (Figure 2). This model is not only suitable for pilot risk management systems, but also has a good application in air traffic control man-made risk control (Lyu et al., 2019). The risk factors are mutually associated and influenced and jointly constitute a set of pilot unsafe behavioural risks. The network relationship of the risk factors at the levels is shown in Figure 3. The factors influencing the unsafe behaviours of general aviation pilots were analysed by referring to the HFACS model framework in the aviation safety management. The main causes for unsafe behaviours were found; thus, this work expects a basis for preventing the occurrence of flight safety accidents while perfecting the investigation report on a general aviation flight accident. However, this model is incomplete in the aspect of structural link division of bottom-layer factors, with a lack of effective method for the quantitative analysis; accordingly, it failed to effectively propose pertinent measures from the organizational and management levels to radically improve pilot skills and their psychological qualities. Moreover, this model could hardly reach the current analytical standards in the field of aviation safety. 
The association rule analytical method was used to figure out the association relationships between item sets in the dataset. This initiative was carried out to take effective measures from the organizational and supervisory levels to end pilot unsafe behaviours and investigate the association relationships of all bottom-layer factors at levels of preconditions for unsafe behaviours, unsafety supervision and organizational influence in the analysis and classification system model with the bottom-layer factors at the level of unsafe behaviours. The support degree, confidence level and lift degree of 14 factors in the preconditions for unsafe behaviours, unsafe supervision and organizational influence in the HFACS model and those of the four factors, namely, skill error, decisionmaking error, cognitive error and violation in unsafe behaviours, were calculated to identify the association relationships between the risk factors. The concrete method is as follows:
The association rule is in similar form of ( $A \Rightarrow B)$, namely, $A_{1} \wedge \cdots \wedge A_{m} \Rightarrow B_{1} \wedge \cdots \wedge B_{n}$, where $A_{i}(i \in\{1, \cdots, m\})$ and $B_{j}(j \in\{1, \cdots, n\})$ constitute one value pair of attribute. The association rule ( $A \Rightarrow B$ ) is explained as 'the database tuples satisfying the condition in $A$ also mostly satisfy the condition in $B^{\prime}$. The association rules are used to analyse and seek for the association between items in a given dataset.

The set of items is called an item set, and the association between item sets is determined through the support degree, confidence level and lift degree, and their measured values are used to measure the association between item sets. The support degree, namely, support ( $A \Rightarrow B$ ), represents the probability for item set $\{A, B\}$ to appear in the total item set, and it is expressed by the following equation:

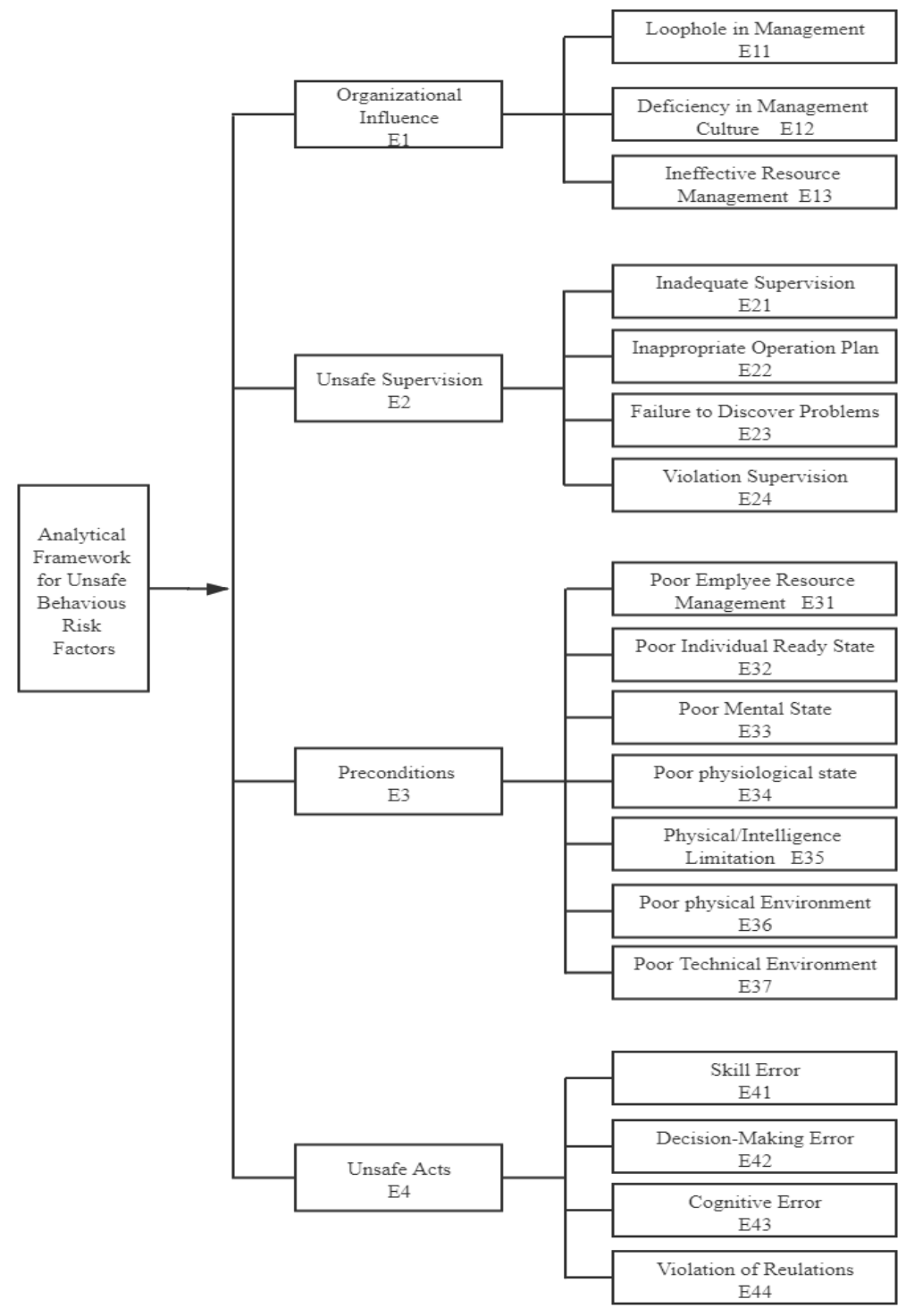

Figure 2. Analytical Framework for the Influencing Factors of Unsafe Behaviours of General Aviation Pilot

support $(A \Rightarrow B)=P(A \cup B)=\operatorname{NUM}(A, B) / \operatorname{MUM}(I)$
where $I$ is total number of transaction sets,
$\operatorname{NUM}(A, B)$ is number of transaction sets containing
$(A, B)$, and $P(A \cup B)$ is the probability for item sets $A$ and $B$ to simultaneously appear. 
Confidence ( $A \Rightarrow B$ ) represents the probability for the association rule $(A \Rightarrow B)$ to deduce $B$ under the occurrence of precondition $A$, namely, the possibility for $B$ to be contained in the item set containing $A$, and it is expressed by the following equation:

$$
\text { Confidence }(A \Rightarrow B)=P(B / A)=P(A \cup B) / P(A)
$$

where $P(B / A)$ is the probability for item set $B$ to occur on the precondition of item set $A$, and $\mathrm{P}(\mathrm{A})$ is the probability for the item set $A$ to occur.

Lift ( $A \Rightarrow B$ ) is the ratio of the probability that $A$ and $B$ are simultaneously contained to the probability that $B$ is contained while $A$ is not contained, and it is expressed by the following equation:

$$
\text { Lift }(A \cup B)=P(B / A) / P(B)
$$

where $P(B)$ is the probability for item set $B$ to occur.

If the association rule ( $A \Rightarrow B$ ) simultaneously satisfies the minimum thresholds of support degree and confidence level, then it is called a strong association rule. Specifically, item set $A$ is strongly associated with item set $B$. The minimum threshold of support degree represents the minimum importance of an item set in statistical significance, that of confidence level represents the minimum reliability of the association rule between item sets, and those of support degree and confidence level are set by the user or expert in the field. However, the strong association rule is divided into valid and invalid strong association rules. If the lift degree is higher than one, namely, Lift $(A \Rightarrow B)>1$, then the association rule ( $A \Rightarrow B$ ) is considered a valid strong association rule. If the lift degree is lower than one, namely, Lift $(A \Rightarrow B)<1$, then the association rule $(A \Rightarrow B)$ is valid strong association rule. If the lift degree is equal to one, namely, Lift $(A \Rightarrow B)=1$, then item sets $A$ and $B$ are mutually independent.

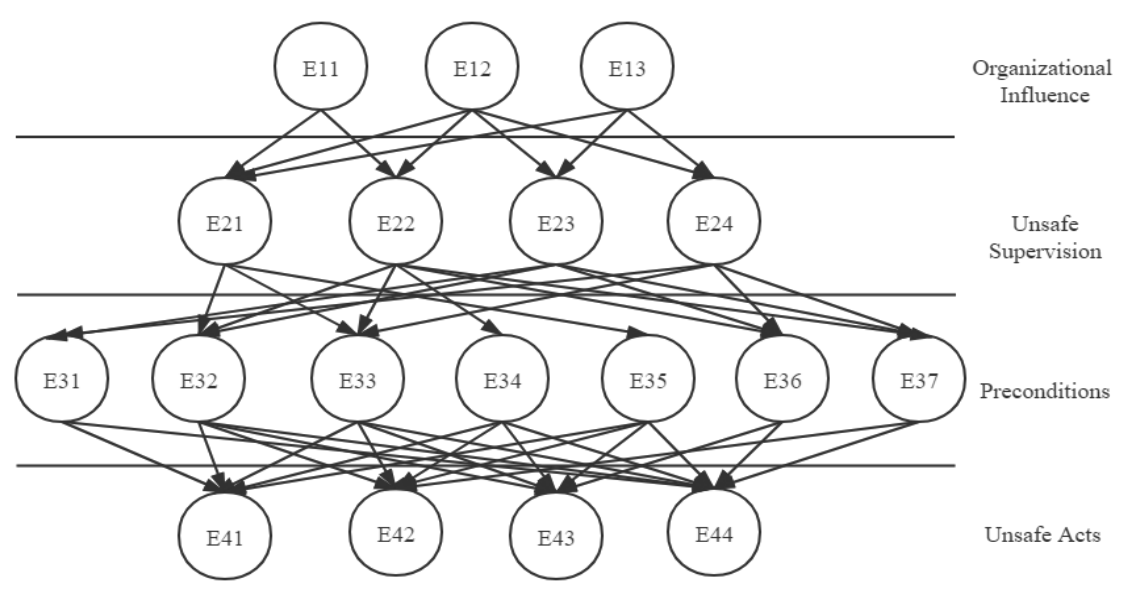

Figure 3. Network Relationship between Factors in the HFACS Model

The DEMATEL system structural modelling method analyses the influencing relationship between any two factors in the system by using the matrix and graph theory (Sumalee, 2019). This method quantifies the logical relationship between factors in the index system through the Delphi method and further establishes the corresponding direct influence matrix. Moreover, this method calculates the influence degrees of the factors on other factors and the degrees to which they are influenced by the other factors by determining the direct influence relationships between factors in the system. This system also distinguishes the causal factors from the result factors and identifies the key factors in the complex system and their influence degrees. Moreover, this method is considered the optimal method of analysing the causal relationships between complex factors in the complex structural model. The concrete process is as follows:

The direct influence degree between factors and the influence matrix are determined. The influence degrees between factors are determined through the Delphi method and scored in digital forms of $0,1,2,3$ and 4 , which represent no influence, very low, low, high and very high influence degrees, respectively. The investigation results demonstrate that the direct influence matrix $X=\left(x_{i j}\right)_{n^{*} n}$ is obtained, where $x_{i j}$ is the direct influence degree of factor $A_{i}$ on factor $A_{j}$, and $x_{i j}=0$ under $i=j$.

The direct influence matrix $\mathrm{X}$ is standardised to obtain the standardised influence matrix $\mathrm{D}$.

$$
\mathrm{D}=\left(1 / \operatorname{Max}_{i=1}^{\mathrm{n}} \sum_{j=1}^{\mathrm{n}} x_{i j}\right) * \mathrm{X}
$$

The DEMATEL fully considers the indirect influence relationships between factors via Eq. (5), where $T$ is comprehensive influence matrix, $I$ is unit matrix, and $T_{i j}$ expresses the direct and indirect influence degrees of factor $A_{i}$ on factor $A_{j}$ or the comprehensive influence degree borne by factor $A_{j}$ from factor $A_{i}$.

$$
T=\mathrm{D} *(I-\mathrm{D})^{-1}
$$

The sum of factors in each row of the comprehensive influence matrix $\mathrm{T}$ is the comprehensive influencing value of the factors in this row on all the other factors (namely, 
the comprehensive influencing factor of the factors in each row on all the other factors), and it is called influence degree $(C)$. The sum of factors in each column of $\mathrm{T}$ is the comprehensive influence value borne by the corresponding factors in this column from all the other factors (namely, the comprehensive influence value borne by the corresponding factors in each row from all the other factors), and it is called the influenced degree $(R)$. The sum of the influence degree and influenced degree of a factor is called $(C+R)$, and it represents the position of this factor in the system, and the effect it exerts. The influence degree of this factor on unsafe behavioural risks of general aviation pilots is high, and the exerted effect will be great when the centrality is high. The difference value between the influence and influenced degrees is called causality $(C-R)$.

$$
\begin{gathered}
C=\left[\sum_{i=1}^{n} t_{i j}\right]_{n^{* 1}}=\left[c_{i}\right]_{n^{* 1}} \\
R=\left[\sum_{j=1}^{n} t_{i j}\right]_{1^{*} n}=\left[r_{j}\right]_{n^{* 1}}
\end{gathered}
$$

If the causality is greater than zero, then this factor has a great influence and is more important than the other unsafe behaviour risk factors; thus, it belongs to a causal factor, which proactively influences the other factors; if the causality is smaller than zero, then this factor can be easily influenced by the other factors. The factors influencing unsafe behaviours belong to result factors. The causal and result factors embody the influencing characteristics of factors. The influence degree $(C)$ and influenced degree $(R)$ of each factor can be calculated according to Eqs. (6) and
(7), and the centrality $(C+R)$ and causality $(C-R)$ corresponding to this factor can be acquired, respectively.

When the Delphi method is used, the fuzzy and unclear characteristics may exist in the expert scoring process. To make the next-step analysis real and accurate, the expert language variable should be transformed into fuzzy data, followed by defuzzification. When the DEMATEL method is used, the influencing relationship scores between system factors given by experts are certain, which do not conform to the current situation. Accordingly, the DEMATEL method was combined with the fuzzy theory considering the uncertainty and fuzziness brought by the subjective assumption of expert evaluation, which could not only avoid the influence brought by the fuzziness of expert scoring but also transform the fuzzy statements made by experts into clear values. Thus, the obtained results became reasonable and accorded with the real situation. The concrete steps of Fuzzy-DEMATEL are presented as follows:

Each factor screened out through the literature analysis and expert interview was regarded as a factor directly or indirectly influencing the index attribute. Experts were invited to judge the direct influencing relationship of each factor with the other factors. The factors were marked at their corresponding positions according to their relationship strength. Specifically, $k$ experts were invited to judge the influences of factor $i$ on $j$ in the matrix. The influence of factor $i$ on $j$ is divided into 'no influence', 'weak influence', 'moderate influence', 'strong influence' and 'very strong influence', which are marked as 'N', 'VL', ' $\mathrm{L}$ ', 'H' and 'VH'. The semantic variables of experts obtained by reference to the literature (Lin, \& Jia, 2016; Jiri, 2019) are illustrated in Table 1.

Table 1

Corresponding Relationship between Expert Evaluation and Triangular Fuzzy Number

\begin{tabular}{|c|c|}
\hline Different semantic variables & Triangular fuzzy numbers \\
\hline No influence $(\mathrm{N})$ & $(0,0,0.25)$ \\
\hline Very low influence $(\mathrm{VL})$ & $(0,0.25,0.25)$ \\
\hline Low influence $(\mathrm{L})$ & $(0.25,0.5,0.75)$ \\
\hline High influence $(\mathrm{H})$ & $(0.5,0.75,1.0)$ \\
\hline Very high influence $(\mathrm{VH})$ & $(0.75,1.0,1.0)$ \\
\hline
\end{tabular}

We assume that $z_{i j}^{k}=\left(l_{i j}^{k}, m_{i j}^{k}, r_{i j}^{k}\right)$ represents the triangular fuzzy evaluation given by exert $i$ regarding the influence of factor $i$ on $j, 1 \leq k \leq K$, where $l$ is a conservative value; $m$ is the value closest to the practice; and $r$ is an optimistic value. The standardization of the triangular fuzzy numbers is as follows:

$$
\begin{aligned}
& x l_{i j}^{k}=l_{i j}^{k}-\min _{1 \leq k \leq K} l_{i j}^{k} / \Delta_{\min }^{\max }, \\
& m l_{i j}^{k}=m_{i j}^{k}-\min _{1 \leq k \leq K} l_{i j}^{k} / \Delta_{\min }^{\max }, \\
& x r_{i j}^{k}=r_{i j}^{k}-\min _{1 \leq k \leq K} l_{i j}^{k} / \Delta_{\min }^{\max }, \\
& \Delta_{\max }^{\min }=\max _{1 \leq k \leq K} r_{i j}^{k}-\min _{1 \leq k \leq K} l_{i j}^{k} .
\end{aligned}
$$

The initial matrix is established. According to the experts' semantic variables in Table 1, the expertise is transformed into the corresponding triangular fuzzy numbers $\left(l_{i j}^{k}, m_{i j}^{k}, r_{i j}^{k}\right)$.

$$
\begin{aligned}
x l s_{i j}^{k} & =\frac{x m_{i j}^{k}}{1+x m_{i j}^{k}-x l_{i j}^{k}}, \\
x r s_{i j}^{k} & =\frac{x r_{i j}^{k}}{1+x r_{i j}^{k}-x m_{i j}^{k}},
\end{aligned}
$$

The total standardised value is calculated as follows:

$$
x_{i j}^{k}=\frac{x l s_{i j}^{k}\left(1-x l s_{i j}^{k}\right)+x r s_{i j}^{k} g x r s_{i j}^{k}}{1+x l s_{i j}^{k}-x r s_{i j}^{k}} .
$$

The post-defuzzification clear value of expert $k$ is calculated as follows:

$$
z_{i j}^{k}=\min _{1 \leq k \leq K} l_{i j}^{k}+x_{i j}^{k} \Delta_{\min }^{\max } .
$$

The average clear value is obtained as follows:

$$
Z_{i j}=\frac{1}{K} \sum_{k=1}^{K} z_{i j}^{k}
$$


where $Z=\left[z_{i j}\right]_{n \times n}$ is a nonnegative matrix.

$$
\begin{aligned}
& N=s g Z, \\
& s=\frac{1}{\max _{1 \leq t \leq n} \sum_{j=1}^{n} z_{i j},},
\end{aligned}
$$

where $i, j=1,2, K, n$.

$$
T=N+N^{2}+N^{3}+L=N(I-N)^{-1},
$$

where $I$ is a unit matrix.

The direct influence matrix $Z$ is standardised according to Eqs. (16) and (17) to obtain the standardised matrix $N$. Meanwhile, the comprehensive influence matrix $T$ ( $T=\left[t_{i j}\right]_{n \times n}$ ) is calculated through Eq. (19).

The centrality and causality values of each influencing factor can be obtained by combining Eqs. (6) and (7) in the DEMATEL method.

The centrality and causality of the influencing factors at four levels, namely, unsafe behaviours of general aviation pilots, preconditions for unsafe behaviours, unsafety supervision and organizational influence, in the HFACS model are taken as the dimensions to establish the Cartesian coordinate system. The importance degrees of the factors and their mutual relationships are judged by labelling their corresponding positions in the coordinate system.

Based on the acquired influencing factor index system of unsafe behaviours of general aviation pilots and the implementation steps of the established Fuzzy-DEMATEL model, the first-hand judgment data were collected from the professionals in general aviation enterprises and experts in the academic field through the questionnaire survey to guarantee the data authenticity and provide support for the subsequent data analysis. The factors were repeatedly compared in the filling to prevent the related experts and management workers within the industry, which would result in the chaotic train of thought and influence the questionnaire authenticity. The common matrix filling mode was improved in this study. A questionnaire similar to the Likert five-point scale was designed to explain the connotations and filling method of the factors in detail for the convenience of expert questionnaire filling. The questionnaires were recovered in the following ways: e-mail and field filling. Fifty questionnaires were given out to 50 authoritative experts and frontline managers within the industry, 48 ones were recovered, and the related statistical data were averaged to support the follow-up establishment of direct adjacency matrix.

\section{Results Analysis and Discussion}

Based on the databases of the U.S National Transportation Safety Board, British Air Accidents Investigation Branch, Transportation Safety Board of Canada, French Accident Investigation Bureau for Civil Aviation, German Civil Aviation Bureau and Civil Aviation Administration of China, the reports of 200 general aviation accidents/potential accidents (15 extraordinarily serious accident, 36 major accident, 53 ordinary accidents and 96 potential accidents) triggered by pilot mistakes during 2010-2019 were collected. The frequencies of bottom-layer factors and their simultaneous occurrence with the factors at the level of unsafe behaviours were calculated on the basis of the classical HFACS model (Table 2), where $A$ represents unsafe behaviour risk factor; $B$ represents the preconditions for unsafe behaviours, unsafety supervision and organizational management; and $T$ is the frequency of the factors in the analytical reports of the 200 accidents.

Table 2

Frequencies of Bottom-Layer Factors and Cooccurrence Frequencies between Factors

\begin{tabular}{|c|c|c|c|c|c|c|c|c|c|c|c|c|c|c|c|}
\hline & A & E11 & E12 & E13 & E21 & E22 & E23 & E24 & E31 & E32 & E33 & E34 & E35 & E36 & E37 \\
\hline B & T & 106 & 62 & 20 & 62 & 17 & 41 & 57 & 63 & 12 & 13 & 60 & 25 & 16 & 64 \\
\hline E41 & 147 & 35 & 24 & 13 & 7 & 12 & 7 & 41 & 37 & 12 & 33 & 41 & 8 & 10 & 21 \\
\hline E42 & 120 & 24 & 13 & 11 & 7 & 12 & 2 & 33 & 34 & 10 & 5 & 29 & 13 & 5 & 38 \\
\hline E43 & 23 & 2 & 4 & 3 & 6 & 4 & 0 & 3 & 4 & 3 & 0 & 0 & 0 & 0 & 7 \\
\hline E44 & 113 & 27 & 20 & 13 & 8 & 5 & 3 & 12 & 27 & 9 & 3 & 8 & 9 & 8 & 19 \\
\hline
\end{tabular}

Table 2 illustrates that in the reports of the 200 aviation accidents/potential accidents, the factors with the highest frequency at the four levels in the Human Factors Analysis and Classification System (HFACS) model are E37 (poor technical environment, 64 times) in the preconditions for unsafe behaviours, E21 (inadequate supervision, 62 times) in the unsafety supervision, E11 (loophole in management process, 106 times) in the deficiency in organizational management and E41 (skill error, 147 times) in the unsafe behaviours. The support degree, confidence level and uplift degree of 14 factors in the preconditions for unsafe behaviours, unsafety supervision and organizational influence and four factors (namely, skill error, decision-making error, cognitive error and violation of regulations) in the unsafe behaviours in the HFACS model were calculated through the association rules analysis method.

Support (poor individual ready state $\rightarrow$ skill error) $=12 / 100=0.06$, confidence (poor individual ready state $\rightarrow$ skill error) $=0.06 / 0.06=1.00$, and Lift (poor individual ready state $\rightarrow$ skill error) $=1.00 / 0.74=1.36$. The calculated results of support degree, confidence level and lift degree between other item sets were acquired. According to the expertise, the statistical results under minimum threshold of support degree of 0.02 , minimum threshold of confidence level of 0.65 and lift degree of $>1$ is presented in Table 3. 
Association Relationships between Bottom-layer Factors

\begin{tabular}{|c|c|c|c|}
\hline $\mathbf{X} \rightarrow \mathbf{Y}$ & Support & Confidence & Lift \\
\hline Poor individual ready state $\rightarrow$ skill error & 0.06 & 1.00 & 1.36 \\
\hline Poor individual ready state $\rightarrow$ decision-making error & 0.05 & 0.83 & 1.39 \\
\hline Poor individual ready state $\rightarrow$ violation & 0.05 & 0.75 & 1.33 \\
\hline Inadequate operation plan $\rightarrow$ decision-making error & 0.06 & 0.71 & 1.18 \\
\hline Ineffective resource management $\rightarrow$ violation & 0.07 & 0.65 & 1.15 \\
\hline
\end{tabular}

Matlab software was used to organise the expert scoring results, and the triangular fuzzy matrix $\left(l_{i j}^{k}, m_{i j}^{k}, r_{i j}^{k}\right)$ between the unsafe behaviour risk factors of general aviation pilots was obtained. Next, the fuzzy matrix was clarified (Liu, \& Ming, 2019) through converting fuzzy data into crisp scores (CFCS) according to Eqs. (12)-(16) to obtain the direct influence matrix as shown in Table 4 (In Appendix).

According to Eqs. (17) and (18), direct influence matrix $Z$ was standardised to obtain the standardised direct influence matrix N. Eq. (19) was used to calculate the comprehensive influence matrix $T\left(T=\left[t_{i j}\right]_{n \times n}\right)$ as demonstrated in Table 5 (Appendix).
The influence degree, influenced degree, centrality and causality of the unsafe behaviour risk factors of general aviation pilots were obtained based on Eqs. (4)-(7) as illustrated in Tables 6 and 7 (Seen in annexes).

According to the numerical results of centrality and causality calculated through the tables, the centrality was taken as the $\mathrm{x}$-coordinate and causality as $\mathrm{y}$-coordinate to depict points in the Cartesian coordinate system via Matlab, and the causal graph was drawn (Figure 4). All causal influence factors were factors above the $\mathrm{x}$-coordinate, while the result influence factors were all beneath the $\mathrm{x}$ coordinate. The $\mathrm{x}$-coordinate value of each influence factor represented the importance degree to this influence factor in the index system of all factors influencing pilot unsafe behaviours.

Table 6

Influence and Influenced Degrees of Factors Influencing Unsafe Behaviours of General Aviation Pilots

\begin{tabular}{|c|c|c|c|c|c|}
\hline \multicolumn{2}{|l|}{ Influencing Factors } & Influence degree $\mathbf{C}$ & Ranking & Influenced degree $\mathrm{R}$ & Ranking \\
\hline \multirow{3}{*}{$\begin{array}{l}\text { Deficiency in organizational management } \\
\text { E1 }\end{array}$} & E11 & 4.9399 & 1 & 4.1823 & 8 \\
\hline & E12 & 3.7985 & 10 & 2.9356 & 15 \\
\hline & E13 & 3.9672 & 8 & 3.6425 & 10 \\
\hline \multirow{4}{*}{$\begin{array}{l}\text { Unsafety supervision } \\
\text { E2 }\end{array}$} & E21 & 4.3259 & 4 & 4.6389 & 5 \\
\hline & E22 & 3.6332 & 13 & 4.1362 & 9 \\
\hline & E23 & 4.1414 & 5 & 5.2399 & 3 \\
\hline & E24 & 4.6582 & 3 & 4.3215 & 7 \\
\hline \multirow{7}{*}{$\begin{array}{l}\text { Preconditions for unsafe behaviours } \\
\text { E3 }\end{array}$} & E31 & 3.1504 & 18 & 3.0354 & 14 \\
\hline & E32 & 3.674 & 11 & 3.2065 & 12 \\
\hline & E33 & 3.9031 & 9 & 3.4736 & 11 \\
\hline & E34 & 3.3165 & 16 & 2.4836 & 17 \\
\hline & E35 & 4.6945 & 2 & 3.1014 & 13 \\
\hline & E36 & 3.5646 & 14 & 1.9147 & 18 \\
\hline & E37 & 3.4855 & 15 & 2.5704 & 16 \\
\hline \multirow{4}{*}{$\begin{array}{l}\text { Unsafe behaviours } \\
\text { E4 }\end{array}$} & E41 & 3.162 & 17 & 4.4255 & 6 \\
\hline & E42 & 3.6721 & 12 & 5.6790 & 2 \\
\hline & E43 & 3.9866 & 7 & 5.1685 & 4 \\
\hline & E44 & 4.0446 & 6 & 5.9627 & 1 \\
\hline
\end{tabular}

Causality and Centrality of Factors Influencing Unsafe Behaviours of General Aviation Pilots

\begin{tabular}{|c|c|c|c|c|c|}
\hline \multicolumn{2}{|l|}{ Influencing Factors } & Centrality $\mathbf{P}$ & Ranking & Causality E & Ranking \\
\hline \multirow{3}{*}{$\begin{array}{l}\text { Deficiency in organizational management } \\
\text { E1 }\end{array}$} & E11 & 9.1222 & 5 & 0.7576 & 6 \\
\hline & E12 & 6.7341 & 14 & 0.8629 & 4 \\
\hline & E13 & 7.6097 & 10 & 0.3247 & 10 \\
\hline \multirow{4}{*}{$\begin{array}{l}\text { Unsafety supervision } \\
\text { E2 }\end{array}$} & E21 & 8.9648 & 7 & -0.313 & 12 \\
\hline & E22 & 7.7694 & 9 & -0.503 & 13 \\
\hline & E23 & 9.3813 & 2 & -1.0985 & 14 \\
\hline & E24 & 8.9797 & 6 & 0.3367 & 9 \\
\hline \multirow{4}{*}{$\begin{array}{l}\text { Preconditions for unsafe behaviours } \\
\text { E3 }\end{array}$} & E31 & 6.1858 & 15 & 0.1150 & 11 \\
\hline & E32 & 6.8805 & 13 & 0.4675 & 7 \\
\hline & E33 & 7.3767 & 12 & 0.4295 & 8 \\
\hline & E34 & 5.8001 & 17 & 0.8329 & 5 \\
\hline
\end{tabular}




\begin{tabular}{|c|c|c|c|c|c|}
\hline \multicolumn{2}{|c|}{ Influencing Factors } & Centrality P & Ranking & Causality E & Ranking \\
\hline \multirow{3}{*}{$\begin{array}{c}\text { Unsafe behaviours } \\
\text { E4 }\end{array}$} & E35 & 7.7959 & 8 & 1.5931 & 2 \\
\cline { 2 - 6 } & $\mathrm{E} 36$ & 5.4793 & 18 & 1.6499 & 1 \\
\cline { 2 - 6 } & $\mathrm{E} 37$ & 6.0559 & 16 & 0.9151 & 3 \\
\hline & $\mathrm{E} 41$ & 7.5875 & 11 & -1.2635 & 16 \\
\cline { 2 - 6 } & $\mathrm{E} 42$ & 9.3511 & 3 & -2.0069 & 18 \\
\cline { 2 - 6 } & $\mathrm{E} 43$ & 9.1551 & 4 & -1.1819 & 15 \\
\cline { 2 - 6 } & $\mathrm{E} 44$ & 10.0073 & 1 & -1.9181 & 17 \\
\hline
\end{tabular}

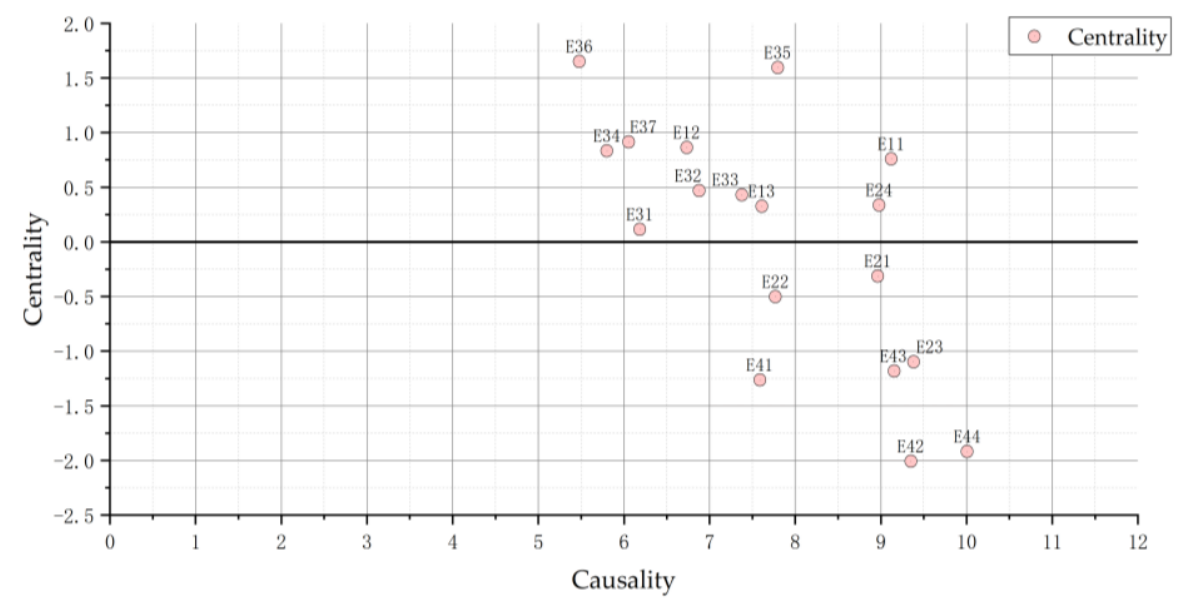

Figure 4. Causal Graph of Factors Influencing Unsafe Behaviours of General Aviation Pilots

The analytical data and the association rules indicated that the poor individual ready state was strongly associated with skill error, decision-making error and habitual violation. If the poor individual ready state in the preconditions for unsafe behaviours took place, then pilot skill error, decision-making error and habitual violation would certainly happen, which was identical with the research result of English (2015) regarding the pilot behaviours in violation of regulations. The probability of occurrence of pilot decision-making error was $83 \%$, and that of violation of regulations was $75 \%$. The valid strong association existed between inadequate operation plan in unsafety supervision and decision-making error. Under the inadequate operation plan, the probability of occurrence of pilot decision-making error was $71 \%$. In the organizational influence, the poor resource management presented the valid strong association with habitual violation. The probability of occurrence of pilot violation under the occurrence of poor resource management reached $65 \%$. According to the aircraft accident analytical report issued by the German State Council, Michael (2006) discussed about the similar associations of the HFACS model indexes from the aspects of pilot error, organizational factors, ergonomic factors, aviation medicine problems and flight crew resource management. This type of risk is inseparable from the pilot training system. The reason is that the rapid development of the civil aviation industry has brought development opportunities to airlines of different levels. However, in some flight unsafe incidents that have occurred in recent years, many pilots have serious shortcomings in their professional skills, such as stress resistance and decisionmaking, which were discovered through accident investigation reports. At present, the training performance evaluation of some low-cost airlines focuses on the control of the completion of the training plan indicators, but there are no corresponding targets and performance management procedures for the training quality. In addition, some airlines do not pay enough attention to soft power, such as the assessment of the training level of the trainer, the training efficiency of the trainee, and the rationalization of the training method. The risk evolution of pilots' unsafe behaviour is the direct cause of civil aviation flight accidents. Small negligence will affect the long-term, healthy and sustainable development of civil aviation and related enterprises. Therefore, airlines must assume relevant social security responsibilities when formulating pilot training systems (Popescu, 2019).

According to the causality values, the influence factors were divided into factors in the cause group (causality $>0$ ) or factors in the result group (causality $<0$ ). The centrality represents the importance degree of each influence factor. When the centrality great, this factor should be considered and highlighted by the enterprise. Given this, starting from the factors in the cause group and result group, the key index factors influencing pilot unsafe behaviours were discussed in this study.

(1) Cause factor analysis

In this research, the cause factors were sorted in a descending order as follows: E36 (poor physical environment), E35 (physical/intelligence limitation), E37 (poor technical environment), E12 (deficiency in management culture), E34 (poor physiological state), E11 (loophole in management process), E32 (poor individual ready state), E33 (poor mental state), E24 (violation supervision), E13 (ineffective resource management) and E31 (poor employee resource management).

E36, E35, E37, E32, E33 and E31 among all the influencing factors and the influencing factors are related to the preconditions for unsafe behaviours ranked in the front, where the causality of E35 (physical/intelligence 
limitation) ranked top 2, and its centrality level ranked top 8 , thereby indicating that this factor was the primary cause for pilot unsafe behaviours. Meanwhile, this factor exerted a great promoting influence on the other factors; thus, it should arouse high attention from aviation enterprises. Rebok (2009) obtained that the pilot decision-making error might be ascribed to differential effects of different ages and levels through the statistics of 1751 flight safety accidents during 1983-2002. The causality values of E36 (poor physical environment) and E37 (poor technical environment) among all the factors ranked tops 1 and 3, respectively; thus, they should have drawn enough attention from general aviation enterprises, but their centrality values took the 18th and 16th places, respectively. The influence degree and influenced degree were at the reciprocal levels in all factors. Therefore, the physical and technical environments were not the most important, though influencing the flight safety level in the flight process. To figure out why, the flight safety is the first 'red line' of the aviation industry; the aircraft maintenance and pilot training in various countries across the globe are at high standard levels and have attracted considerable importance, with preliminary results achieved (Pittaway, 2019). Although the technical and physical environments had a direct bearing on the pilot operating state in the flight process, they did not influence the pilot unsafe behaviours to the greatest extent. Secondly, the causality values of E32 (poor individual ready state), E33 (poor mental state) and E31 (poor employee resource management) among all the factors also ranked in the front; the above data also accorded with the practical process (Jiang, 2019). Furthermore, E12 (deficiency in management culture), E11 (loophole in management process) and E13 (ineffective resource management) also belonged to cause factors. The three factors and the influencing factors related to the deficiency in organizational management took the $4^{\text {th }}$, $6^{\text {th }}$ and $11^{\text {th }}$ places in the aspect of causality level. This notion manifests that the deficiency in the organizational management was the deep cause for pilot unsafe behaviours. The high centrality represented that the aviation enterprises should lay greater emphasis on such risk indexes for the prevention and control, which was expounded and demonstrated by Ancel (2015), Kelly (2019) and Wang et al. (2014) from different levels by using various methods.

\section{(2) Result factor analysis}

The result factors could easily vary with the external conditions due to the great influence of the other factors. The descending order of the result factors was: E21 (insufficient supervision), E22 (inadequate operation plan), E23 (failure to discover and correct problems), E43 (cognitive error), E41 (skill error), E44 (violation of regulations) and E42 (decision-making error). From the level of unsafety supervision, E21 (insufficient supervision), E22 (inadequate operation plan) and E23 (failure to discover and correct problems) belonged to result factors, with centrality values of 7,9 and 2 , respectively. This notion indicates that the two factors, namely, E21 (insufficient supervision) and E22 (inadequate operation plan), had no high influence degrees on the whole system, and their importance degrees were also at general levels. However, the centrality of E23 (failure to discover and correct problems) ranked top 2 among all indexes, which means that the influence of this factor on pilot unsafe behaviours was affected by the external factors to a great extent; this condition might spread among the pilots in the form of 'Herd Effect'; thus, this factor played a significant role in causing the flight accidents (Li, 2013). From the level of unsafe behaviours, the centrality values of E43 (cognitive error), E41 (skill error), E44 (violation of regulations) and E42 (decisionmaking error) took the $4^{\text {th }}, 11^{\text {th }}, 1^{\text {st }}$ and $3^{\text {rd }}$ places, respectively. All indexes at this level, except for E41 (skill error), had great centrality values. The centrality of E44 (violation of regulations) even ranked top 1, thus indicating that the factors at this level exerted extremely important influences on the other factors and promoted them; meanwhile, the violation of regulations was a direct factor causing unsafe behaviours and potential flight accidents (Rebok et al., 2005). Therefore, the aviation enterprises should formulate critical prevention and control measures and corresponding emergency management system to cope with these risk factors.

\section{Conclusions}

Directing at the factors influencing unsafe behaviours of general aviation pilots and their interaction mechanism, the association rule analytical method was utilised to explore the association relationships between the factors based on the HFACS model. The influencing factors were analysed by combining the fuzzy theory with DEMATEL method. The influencing degree, influenced degree, centrality and causality of each factor influencing pilot unsafe behaviours were obtained. The cause factors were distinguished from the result factors, and their importance degrees were obtained. The following conclusions were drawn:

(1) Based on the data statistics, the association rules method can deeply probe into the relationships between the bottom-layer factors in the HFACS model and quantitatively clarify the action mechanisms of the bottom-layer factors at the levels of preconditions for unsafe behaviours, unsafety supervision and organizational influence on the factors at the level of unsafe behaviours. In addition, the poor individual ready state is strongly associated with skill error, decisionmaking error and habitual violation. The valid strong association exists between inadequate operation plan in unsafety supervision and decision-making error. The poor resource management presents that the valid strong association with habitual violation.

(2) The Fuzzy-DEMATEL analytical model can effectively distinguish the causality and result values of the factors influencing pilot unsafe behaviours. This model can also realise the deep analysis of the influencing relationships between risk factors and their influence mechanisms. The causality values of poor physical environment, physical/intelligence limitation, poor technical environment and deficiency in management culture are high. These factors are the reasons that actively influence other risk factors. So are the result degrees of insufficient supervision, inadequate operation plan, failure to discover and correct problems and cognitive error. These factors are more likely to be affected by other factors and lead to unsafe behaviours. Moreover, the 
factors with great causality values influence the factors with great result values.

(3) The Fuzzy theory can realise the defuzzification of expert scoring data, thus guaranteeing the authenticity of original data. If this theory is combined with the DEMATEL analytical model, it can rapidly obtain the centrality results of risk factors and their rankings. The integration of the two methods can realise the systematic identification and analysis of pilot unsafe behaviours from the qualitative and quantitative aspects, thus providing a practical and feasible decision-making method for the improvement of flight safety management level of general aviation enterprises.

Specifically, the association rule analytical and FuzzyDEMATEL methods can clarify the influencing levels of risk factors when applied to the analysis of pilot unsafe behaviour risk factors in the general aviation industry.
These methods can be used to divide the influencing levels and paths of the factors by distinguishing the cause factors from the result factors. This study provides an accurate theoretical support for formulating the prevention and control measures specific to human risk factors. However, when assigning values to the bottom-layer factors, this study relied upon the expertise to a great extent. Meanwhile, how the unsafe behaviour risks are transferred on the influence paths, and how to intercept the risk transfer paths to construct a comprehensive prevention and control system for the unsafe flight behaviours remain to be further investigated. In the future, we believe that the pilot's unsafe behaviours data collection and analysis system based on information technology is one of the effective measures to effectively deal with the risks of general aviation flight. These all constitute the next research direction of this article.

\section{Acknowledgements}

This study was funded by the Science and Technology Planning Project of Henan Province in China (No. 202102310384, 192102310253 and 202102310456) and Postdoctoral Research Fund of Anyang Institute of Technology (No. BSJ2020002) and Science and Technology Planning Project of Anyang in Henan Province (No. 2021C01SF042) and Training Program for Young Backbone Teachers in Colleges and Universities of Henan Province (No. 2020GGJS174)

\section{References}

Ancel, E., Shih, A. T., \& Jones, S. M. (2015). Predictive safety analytic: inferring aviation accident shaping factors and causation. Journal of Risk Research, 18(4), 428-451. https://doi.org/10.1080/13669877.2014.896402

Benlemlih, M., \& Cai, L. (2020). Corporate environmental performance and financing decisions. Business Ethics: A European Review, 29(2), 248-265. https://doi.org/10.1111/beer.12257

Casner, S. M., Geven, R. W., \& Williams, K. T. (2013). The effectiveness of airline pilot training for abnormal events. Human Factors, 55(3), 477-485. https://doi.org/10.1177/0018720812466893

Catherwood, D., Edgar, G. K., \& Nikolla, D. (2014). Mapping brain activity during loss of situation awareness: an EEG investigation of a basis for top-down influence on perception. Human Factors, 56(8), $1428-1452$. https://doi.org/10.1177/0018720814537070

Chaturvedi A. K., Craft K. J., \& Hickerson J. S. (2016). Ethanol and drugs found in civil aviation accident pilot fatalities, 1989-2013. Aerospace Medicine \& Human Performance, 87(5), 470-476. https://doi.org/10.3357/AMHP.4490.2016

Chen, C. F., \& Chen, S. C. (2014). Measuring the effects of Safety Management System practices, morality leadership and self-efficacy on pilots' safety behaviors: Safety motivation as a mediator. Safety Science, 62, $376-385$. https://doi.org/10.1016/j.ssci.2013.09.013

Dambier, M., \& Hinkelbein, J. (2006). Analysis of 2004 German general aviation aircraft accidents according to the HFACS model. Air Medical Journal, 25(6), 265-269. https://doi.org/10.1016/j.amj.2006.03.003

English, D., \& Branaghan, R. J. (2015). An empirically derived taxonomy of pilot violation behavior. Safety Science, 50(2), 199-209. https://doi.org/10.1016/j.ssci.2011.08.009

Erjavac, A. J., Ronald, I., \& Fossaceca, J. M. (2018). Evaluation of preconditions affecting symptomatic human error in general aviation and air carrier aviation accidents. Reliability Engineering \& System Safety, 178, $156-163$. https://doi.org/10.1016/j.ress.2018.05.021

Gan, X. S., Cui, H. L., \& Gao, W. M. (2015). Analysis and suggestion of midair collision accident based on HFACS. Journal of Safety Science and Technology, 11(10), 96-102. https://doi.org/10.11731/j.issn.1673-193x.2015.10.017

Huo, Z. L., Xie, Z. N., \& Zhang, Y. (2011). Research on the framework of safety recommendations for human factor in aviation accident investigation. Journal of Safety Science and Technology, 7(2), 91-97.

Ji, M., Yang, C., \& Li, Y. (2018). The influence of trait mindfulness on incident involvement among Chinese airline pilots: The role of risk perception and flight experience. Journal of Safety Research, 66, 161-168. https://doi.org/10. 1016/j.jsr.2018.07.005

Ji, M., You, X., \& Lan, J. (2011). The impact of risk tolerance, risk perception and hazardous attitude on safety operation among airline pilots in China. Safety Science, 49(10), 1412-1420. https://doi.org/10.1016/j.ssci.2011.06.007 
Xinyao Guo, Yue Chen, Qingmin Si, Yuansheng Wang. Evolution Mechanism on the Unsafe Behavioural Risks...

Jiang, H., Shi, R., \& Yang, J. Z. (2019). Establishment of a QAR date-based model for assessing safety capabilities in airline pilots. Space Medicine and Medical Engineering, 32(3), 208-212. https://doi.org/10.16289/j.cnki.10020837.2019.03.004

Jiri, S. (2019). Sales forecasting in financial distribution: a comparison of quantitative forecasting methods. Journal of Financial Services Marketing, 24, 69-80. https://link.springer.com/article/10.1057/s41264-019-00068-3. https://doi.org/ 10.1057/s41264-019-00068-3

Kelly, D., \& Efthymiou, M. (2019). An analysis of human factors in fifty controlled flight into terrain aviation accidents from 2007 to 2017. Journal of Safety Research, 69, 155-165. https://doi.org/10.1016/j.jsr.2019.03.009

Kyriakopoulos, G., Ntanos, S., \& Anagnostopoulos, T. T. (2020). Internet of Things (IoT)-Enabled Elderly Fall Verification, Exploiting Temporal Inference Models in Smart Homes. International Journal of Environmental Research and Public Health, 17(2), 408. https://doi.org/10.3390/ijerph17020408

Li, W. C., Harris, D., \& Yu, C. S. (2008). Routes to failure: Analysis of 41 civil aviation accidents from the Republic of China using the human factors analysis and classification system. Accident Analysis \& Prevention, 40(2), $426-434$. https://doi.org/10.1016/j.aap.2007.07.011

Li, Z. (2013). Study on Threats and Error Management in Aviation through a Serious Incident. Journal of Civil Aviation Flight University of China, 24(5), 24-27.

Lin, X. H., \& Jia, W. H. (2016). FMEA method combining OWA operator and fuzzy DEMATEL. Computer Science, 43(11), 362-367.

Liu, R. H. (2019). Research on internal and external factors and mechanism affecting pilot's flight unsafe behaviors. Master Degree: Civil Aviation University of China.

Liu Z., \& Ming, X. A. (2019). framework with revised rough-DEMATEL to capture and evaluate requirements for smart industrial product-service system of systems. International Journal of Production Research, 57(21), 7104-7122. https://doi.org/10.1080/00207543.2019.1577566

Lyu, T, Song, W. B., \& Du, K. (2019). Human Factors Analysis of Air Traffic Safety Based on HFACS-BN Model. Applied Sciences, 9(23), 5049. https://doi.org/10.3390/app9235049

Mallika, T. (2019). Corporate social responsibility and accountability: a new theoretical foundation for regulating CSR. International Journal of Corporate Social Responsibility, 5, 2. https://doi.org/10.1186/s40991-019-0045-8

Michalski, D. J., \& Bearman, C. (2014). Factors affecting the decision making of pilots who fly in Outback Australia. Safety Science, 68(10), 288-293. https://doi.org/10.1016/j.ssci.2014.03.005

Neuhaus, C., Dambier, M., \& Glaser, E. (2015). Probabilities for severe and fatal injuries in general aviation accidents. Journal of Aircraft, 47(6), 2017-2020. https://doi.org/10.2514/1.C000263

Piotr, G., Jolanta, Z., \& Piotr, K. (2020). The selected problems of public transport organization using mathematical tools on the example of Poland. Tehnicki Glasnik-Technical Journal, 14(3), 375-380. https://doi.org/10.31803/tg20200706182110

Pittaway, N. (2019). Good to Go A 21st century Pilot Training System. Australian Defence Magazine, $27(2), 68-81$.

Popescu. (2019). Corporate Social Responsibility, Corporate Governance and Business Performance: Limits and Challenges Imposed by the Implementation of Directive 2013/34/EU in Romania. Sustainability, 11(19), 5146. https://doi.org/10.3390/su11195146

Rebok, G. W., Qiang, Y., \& Baker, S. P. (2005). Age, Flight Experience, and Violation Risk in Mature Commuter and Air Taxi Pilots. International Journal of Aviation Psychology, 15(4), 363-374. https://doi.org/10.1207/s1532 7108ijap1504_4

Rebok, G. W., Qiang, Y., \& Baker, S. P. (2009). Pilot Age and Error in Air Taxi Crashes. Aviation Space \& Environmental Medicine, 80(7), 647-651. https://doi.org/10.3357/ASEM.2369.2009

Ryffel, C. P., Muehlethaler, C. M., \& Huber, S. M. (2019). Eye tracking as a debriefing tool in upset prevention and recovery training (UPRT) for general aviation pilots. Ergonomics, 62(2), 319-329. https://doi.org/10.1080/001401 39.2018.1501093

Salmon, P. M., Cornelissen, M., \& Trotter, M. J. (2012). Systems-based accident analysis methods: A comparison of Accimap, HFACS, and STAM. Safety Science, 50(4), 1158-1170. https://doi.org/10.1016/j.ssci.2011.11.009

Schultz, M. D., \& Seele, P. (2019). Conceptualizing data-deliberation: The starry sky beetle, environmental system risk, and Habermasian CSR in the digital age. Business Ethics: A European Review, 29(2), 303-313. https://doi.org/10.1 111/beer.12256

Shappell, S., Detwiler, C., \& Holcomb, K. (2007). Human Error and Commercial Aviation Accidents: An Analysis Using the Human Factors Analysis and Classification System. Human Factors, 49(2), 227-242. https://doi.org/10.151 8/001872007X312469 
Suhir, E., \& Mogford, R. H. (2015). Two men in a cockpit: Casualty likelihood if one pilot becomes incapacitated. Journal of Aircraft, 48(4), 1309-1314. https://doi.org/10.2514/1.C031263

Sumalee, S. (2019). A graph-based algorithm for interpersonal ties clustering in signed networks. Tehnicki GlasnikTechnical Journal, 13(4), 275-279. https://doi.org/10.31803/tg-20191104192845

Uribetxebarria, J., Besga, J. M., \& Mendizabal, B. (2020). Intelligent and connected equipment to optimize its life cycle. DYNA, 95(2), 124-124. https://doi.org/10.6036/9404

Usatorre, L., Nino, M., Tames, P., \& Gorrochategui, A. (2020). Online marketplace for suppliers and manufacturing equipment. DYNA, 95(2), 127-12. https://doi.org/10.6036/9409

Wang, Y. G., Yang, C. X., \& Chen, F. (2014). Study on relationship between pilots flying skills and safety performance. China Safety Science Journal, 24(3), 126-131. https://doi.org/10.16265/j.cnki.issn1003-3033.2014.03.016

Wang, Y. G., Zhang, Y., \& Chen, F. (2013). Simulation research on pilots violations evolution based on system dynamics. China Safety Science Journal, 23(12), 28-34. https://doi.org/10.16265/j.cnki.issn1003-3033.2013.12.004

Whinnery, J. E., Canfield, D. V., \& Craft, K. J. (2005). Toxicological findings from 1587 civil aviation accident pilot fatalities, 1999-2003. Aviation Space \& Environmental Medicine, 76(12), 1145-1150. https://doi.org/10.1111/j.1467842X.2005.tb00258.x

Wurthmann, K. (2020). How group and perceiver characteristics affect collective blame following counterproductive work behavior. Business Ethics: A European Review, 29(1), 212-226. https://doi.org/10.1111/beer.12251

Xue, H. J., Liu, W. M., \& Wang, Y. L. (2013). Analysis on pilot's behavior shaping factors upon aviation case base. Advanced Materials Research, 798, 930-935. https://doi.org/10.4028/www.scientific.net/AMR.798-799.930

You, X. Q., Ji M., \& Dai, K. (2009). Developing a multidimensional scale to assess safety behaviors in airline flight. Acta Psychologica Sinica, 41(12), 1237-1251. https://doi.org/10.1360/972009-782

\section{Authors' biographies}

Xinyao Guo, Ph.D., he graduated from the Wuhan University of Technology with a Ph.D., and he is a lecturer at the Zhengzhou University of Aeronautics. He is also a postdoctor at the Henan Polytechnic University. In recent years, as the key member of the International Joint Laboratory for Civil Aviation Safety and Reliability of Henan Province, he has managed and participated over 8 China national and provincial scientific research projects and published more than 15 academic papers in international academic journals. His main research areas are air accident emergency management, risk assessment and engineering risk analysis.

Yue Chen, Master Degree, she graduated from the Northeastern University of China with a master degree, and she is a senior engineer at the Draexlmaier (Benxi) Automotive Electrics Co., Ltd. And she is the director of the security department at the company. In recent years, she has presided over and completed the construction of the enterprise occupational health and safety management system, the safety production standardization system, the hidden danger investigation and the safety risk classification system in the enterprise. She has invented 2 patents and published more than 10 academic papers. Her main research areas are production safety management.

Qingmin Si, Ph.D., he is an associate professor at Zhengzhou University of Aeronautics, received his PhD degree from Northeastern University of China. He is a young backbone teacher of higher education institutions in Henan Province, a first-class safety evaluator in China, a national certified safety engineer, an expert of Henan Aviation Industry Association, and an emergency management expert of Zhengzhou city. In recent years, he has managed and participated over 8 China national and provincial scientific research projects. His main research areas are civil aviation safety management, accident risk investigation and urban safety assessment.

Yuansheng Wang, Ph.D., she received her Ph.D. degree from Henan Polytechnic University in 2019, and she is a lecturer at the Anyang Institute of Technology. She is also a postdoctor at the Henan Polytechnic University. As a major member of the Human-Machine-Environment Key Laboratory of Henan Province in China, she has gone to Japan, Taiwan and other high-level universities for scientific research exchanges and made 3 high-level academic reports. In recent years, she has managed and participated over 5 China national and provincial scientific research projects and published more than 10 academic papers in international academic journals. Her research areas are risk analysis and Man-MachineEnvironment system engineering.

The article has been reviewed.

Received in December 2020; accepted in April 2021.

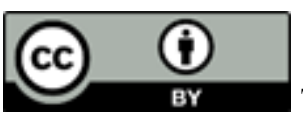

This article is an Open Access article distributed under the terms and conditions of the Creative Commons Attribution 4.0 (CC BY 4.0) License (http://creativecommons.org/licenses/by/4.0/). 
Annexes

Table 4

Judgment of Direct Influence Relationships of Factors Influencing Unsafe Behaviours of General Aviation Pilots

\begin{tabular}{|c|c|c|c|c|c|c|c|c|c|c|c|c|c|c|c|c|c|c|}
\hline Factors & E11 & E12 & E13 & E21 & E22 & E23 & E24 & E31 & E32 & E33 & E34 & E35 & E36 & E37 & E41 & E42 & E43 & E44 \\
\hline E11 & - & 0.1726 & 0.7321 & 0.6382 & 0.3343 & 0.3129 & 0.3874 & 0.2135 & 0.0371 & 0.0103 & 0.0036 & 0.0015 & 0.1826 & 0.2396 & 0.3582 & 0.4371 & 0.1327 & 0.6351 \\
\hline E12 & 0.6529 & - & 0.1846 & 0.3860 & 0.1635 & 0.2635 & 0.2947 & 0.3215 & 0.1000 & 0.0436 & 0.0153 & 0.0021 & 0.1036 & 0.1642 & 0.0942 & 0.0312 & 0.0021 & 0.0013 \\
\hline E13 & 0.2184 & 0.2743 & - & 0.1037 & 0.3173 & 0.0331 & 0.5219 & 0.4210 & 0.1038 & 0.0010 & 0.0012 & 0.0015 & 0.1001 & 0.1026 & 0.0132 & 0.0436 & 0.2164 & 0.4512 \\
\hline E21 & 0.3171 & 0.1362 & 0.4721 & - & 0.6328 & 0.2947 & 0.3263 & 0.1027 & 0.0090 & 0.1038 & 0.0017 & 0.0001 & 0.0001 & 0.0007 & 0.3282 & 0.5439 & 0.4213 & 0.8371 \\
\hline E22 & 0.3462 & 0.1003 & 0.3742 & 0.4127 & - & 0.1937 & 0.1742 & 0.0012 & 0.0018 & 0.1000 & 0.0033 & 0.0012 & 0.0015 & 0.0012 & 0.1323 & 0.6433 & 0.4171 & 0.4217 \\
\hline E23 & 0.4126 & 0.2164 & 0.3826 & 0.3279 & 0.2194 & - & 0.2732 & 0.0047 & 0.0036 & 0.0037 & 0.0010 & 0.0021 & 0.0013 & 0.0028 & 0.3271 & 0.6328 & 0.5218 & 0.3632 \\
\hline E24 & 0.5134 & 0.4137 & 0.4623 & 0.7721 & 0.2947 & 0.5492 & - & 0.1843 & 0.0062 & 0.0012 & 0.0018 & 0.0083 & 0.0019 & 0.0021 & 0.4728 & 0.3279 & 0.5371 & 0.8326 \\
\hline E31 & 0.2633 & 0.0153 & 0.1374 & 0.1264 & 0.1028 & 0.3148 & 0.2473 & - & 0.3179 & 0.1039 & 0.0021 & 0.0002 & 0.0083 & 0.0030 & 0.2847 & 0.2157 & 0.1838 & 0.2737 \\
\hline E32 & 0.1753 & 0.0061 & 0.1000 & 0.0327 & 0.1328 & 0.3857 & 0.1274 & 0.0037 & - & 0.3726 & 0.3274 & 0.0038 & 0.0027 & 0.0015 & 0.3282 & 0.3722 & 0.1023 & 0.3746 \\
\hline E33 & 0.3256 & 0.0021 & 0.1012 & 0.2162 & 0.0032 & 0.4127 & 0.1180 & 0.1037 & 0.3892 & - & 0.1937 & 0.0032 & 0.0018 & 0.0017 & 0.3721 & 0.4210 & 0.0017 & 0.4753 \\
\hline E34 & 0.1789 & 0.0015 & 0.0282 & 0.1460 & 0.0037 & 0.3271 & 0.1047 & 0.0094 & 0.3845 & 0.6439 & - & 0.0011 & 0.0006 & 0.0028 & 0.2848 & 0.1739 & 0.0012 & 0.2716 \\
\hline E35 & 0.2146 & 0.0053 & 0.2174 & 0.1001 & 0.0016 & 0.3746 & 0.1362 & 0.0027 & 0.2652 & 0.6215 & 0.4857 & - & 0.0010 & 0.0002 & 0.8261 & 0.8271 & 0.7215 & 0.1735 \\
\hline E36 & 0.0043 & 0.0013 & 0.3179 & 0.0022 & 0.1032 & 0.1847 & 0.1003 & 0.0382 & 0.0083 & 0.4372 & 0.2842 & 0.0010 & - & 0.1832 & 0.2735 & 0.1012 & 0.2157 & 0.2836 \\
\hline E37 & 0.0122 & 0.0016 & 0.3572 & 0.0012 & 0.1047 & 0.2194 & 0.0036 & 0.0043 & 0.0019 & 0.2847 & 0.0013 & 0.0031 & 0.0372 & - & 0.8362 & 0.2148 & 0.3648 & 0.3521 \\
\hline E41 & 0.6352 & 0.1372 & 0.1236 & 0.0027 & 0.1084 & 0.4623 & 0.0273 & 0.0039 & 0.1038 & 0.1289 & 0.0082 & 0.0011 & 0.0002 & 0.2831 & - & 0.3216 & 0.3265 & 0.2476 \\
\hline E42 & 0.3591 & 0.2648 & 0.3262 & 0.0137 & 0.3857 & 0.2184 & 0.0327 & 0.1028 & 0.1008 & 0.0338 & 0.0027 & 0.0002 & 0.0073 & 0.4622 & 0.1037 & - & 0.4218 & 0.4261 \\
\hline E43 & 0.4218 & 0.2846 & 0.3572 & 0.2183 & 0.3218 & 0.2746 & 0.1038 & 0.2469 & 0.0372 & 0.1039 & 0.0021 & 0.0008 & 0.0018 & 0.0189 & 0.1012 & 0.2937 & - & 0.2183 \\
\hline E44 & 0.6345 & 0.1521 & 0.4723 & 0.4723 & 0.1748 & 0.3274 & 0.5627 & 0.1843 & 0.0302 & 0.0031 & 0.0010 & 0.0019 & 0.0024 & 0.0821 & 0.1003 & 0.3127 & 0.3180 & - \\
\hline
\end{tabular}

Table 5

Comprehensive Influence Matrix for Factors Influencing Unsafe Behaviours of General Aviation Pilots

\begin{tabular}{|c|c|c|c|c|c|c|c|c|c|c|c|c|c|c|c|c|c|c|}
\hline Factors & E11 & E12 & E13 & E21 & E22 & E23 & E24 & E31 & E32 & E33 & E34 & E35 & E36 & E37 & E41 & E42 & E43 & E44 \\
\hline E11 & 0.4826 & 0.2017 & 0.2426 & 0.5831 & 0.3096 & $\begin{array}{l}0.338 \\
\end{array}$ & 0.3319 & 0.251 & $\begin{array}{l}0.1837 \\
\end{array}$ & 0.0731 & 0.011 & $\begin{array}{l}0.1837 \\
\end{array}$ & 0.2183 & 0.2827 & 0.2736 & 0.3182 & 0.1523 & 0.5028 \\
\hline E12 & 0.2846 & 0.5482 & 0.1028 & 0.3142 & 0.1291 & 0.3028 & 0.2513 & 0.3127 & 0.1736 & 0.0634 & 0.0927 & 0.173 & 0.1863 & 0.2816 & 0.1827 & 0.1038 & 0.102 & 0.1937 \\
\hline E13 & 0.3512 & 0.2182 & 0.5129 & 0.1937 & 0.2184 & 0.1384 & 0.4486 & 0.3992 & 0.1194 & 0.1083 & 0.0651 & 0.1378 & 0.1937 & 0.1732 & 0.103 & 0.1096 & 0.2028 & 0.2737 \\
\hline E21 & 0.1083 & 0.1527 & 0.2087 & 0.2169 & 0.4528 & 0.2873 & 0.3016 & 0.1652 & 0.1038 & 0.1149 & 0.0742 & 0.2177 & 0.0726 & 0.0718 & 0.2877 & 0.3829 & 0.3916 & 0.7152 \\
\hline E22 & 0.1812 & 0.1039 & 0.2134 & 0.3523 & 0.3306 & 0.2081 & 0.1861 & 0.1092 & 0.1129 & 0.0946 & 0.0836 & 0.1272 & 0.1826 & 0.0523 & $\begin{array}{l}0.1733 \\
\end{array}$ & 0.4163 & 0.4028 & 0.3028 \\
\hline E23 & 0.2182 & 0.2185 & 0.2369 & 0.2894 & 0.252 & 0.3378 & 0.2452 & 0.1108 & 0.1033 & 0.0542 & 0.1038 & 0.173 & 0.158 & 0.0937 & 0.3198 & 0.4927 & 0.4148 & 0.3193 \\
\hline E24 & 0.172 & 0.2897 & 0.2103 & 0.6947 & 0.2193 & 0.4679 & 0.2615 & 0.1752 & 0.1472 & 0.0635 & 0.1162 & 0.1742 & 0.0261 & 0.0542 & 0.3082 & 0.3819 & 0.367 & 0.5291 \\
\hline E31 & 0.1127 & 0.1265 & 0.1521 & 0.1589 & 0.1582 & $\begin{array}{l}0.298 \\
\end{array}$ & 0.2831 & 0.1732 & 0.2863 & 0.1452 & 0.1043 & 0.127 & 0.0873 & 0.0836 & 0.2135 & 0.2972 & 0.1249 & 0.2184 \\
\hline E32 & 0.2073 & 0.1439 & 0.1028 & 0.1037 & 0.1946 & 0.3154 & 0.2097 & 0.1007 & 0.2986 & 0.2836 & 0.3082 & 0.1183 & 0.0734 & 0.0948 & 0.2973 & 0.3517 & 0.1762 & 0.2938 \\
\hline E33 & 0.3927 & 0.116 & 0.0217 & 0.2597 & 0.1037 & 0.3528 & 0.1981 & 0.0923 & 0.3163 & 0.2973 & 0.2017 & 0.2184 & 0.067 & 0.0513 & 0.3208 & 0.401 & 0.1096 & 0.3827 \\
\hline E34 & 0.1167 & 0.0527 & 0.0423 & 0.2178 & 0.1489 & 0.3045 & 0.1722 & 0.0272 & 0.3045 & 0.4525 & 0.2936 & 0.2032 & 0.0735 & 0.0744 & 0.2193 & 0.2084 & 0.1038 & 0.301 \\
\hline E35 & 0.1033 & 0.0923 & 0.1699 & 0.0362 & 0.1587 & 0.3419 & 0.2089 & 0.1038 & 0.216 & 0.4927 & 0.3725 & 0.2746 & 0.0672 & 0.0275 & 0.5214 & 0.6729 & 0.6329 & 0.2018 \\
\hline E36 & 0.1424 & 0.0728 & 0.2874 & 0.0645 & 0.1903 & 0.2088 & 0.1596 & 0.1562 & 0.1846 & 0.5281 & 0.1937 & 0.1947 & 0.1632 & 0.1037 & 0.1836 & 0.1836 & 0.2725 & 0.2749 \\
\hline E37 & 0.1037 & 0.1 & 0.2903 & 0.073 & 0.1877 & 0.2317 & 0.1149 & 0.2183 & 0.142 & 0.2037 & 0.0752 & 0.1741 & 0.0541 & 0.1529 & 0.5124 & 0.2027 & 0.3515 & 0.2973 \\
\hline E41 & 0.3096 & 0.0182 & 0.0921 & 0.1021 & 0.1762 & 0.3572 & 0.1744 & 0.1038 & 0.1129 & 0.1692 & 0.0947 & 0.1528 & 0.0892 & 0.2825 & 0.0725 & 0.3167 & 0.3196 & 0.2183 \\
\hline E42 & 0.2168 & 0.2378 & 0.2068 & 0.1837 & 0.3249 & 0.2083 & 0.1083 & 0.1651 & $\begin{array}{l}0.1194 \\
\end{array}$ & 0.1094 & 0.0836 & $\begin{array}{l}0.1027 \\
\end{array}$ & 0.0717 & 0.3927 & $\begin{array}{l}0.1273 \\
\end{array}$ & 0.2836 & 0.3772 & 0.3528 \\
\hline $\mathbf{E 4 3}$ & 0.3769 & 0.2144 & 0.2774 & 0.2927 & 0.3765 & 0.2514 & 0.1982 & 0.1792 & 0.1735 & 0.1101 & 0.1012 & 0.1654 & 0.0765 & 0.1937 & 0.137 & 0.2742 & 0.2844 & 0.3039 \\
\hline E44 & 0.3021 & 0.0281 & 0.2721 & 0.5023 & 0.2047 & 0.2896 & 0.4679 & 0.1923 & 0.1085 & 0.1098 & 0.1083 & 0.1836 & 0.054 & 0.1038 & 0.1721 & 0.2816 & 0.3826 & 0.2812 \\
\hline
\end{tabular}

